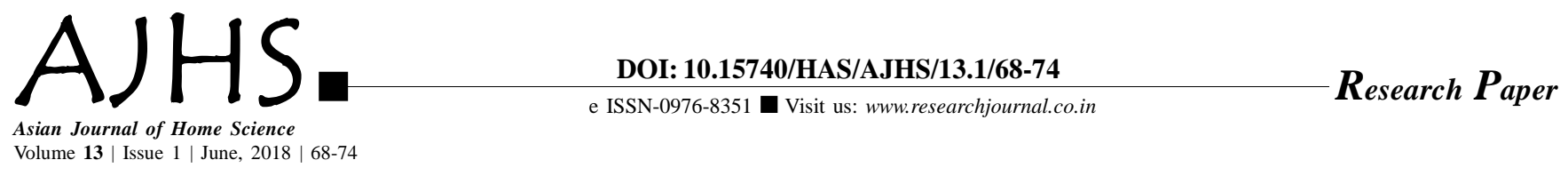

\title{
An application of generalized linear model in survival analysis
}

Yasmeena Ismail, S.A Mir, M.A Bhat and Nageena Nazir

Received: 17.12.2017; Revised: 19.03.2018; Accepted: 05.04.2018

See end of the paper for authors' affiliations

\section{Nageena Nazir}

S.K. University of Agricultural

Sciences and Technology of

Kashmir, Shalimar, Srinagar

(J\&K) India

Email : nazir.nageena@gmail.com
ABSTRACT : Diabetes is a chronic, often debilitating and sometimes fatal disease, in which the body either cannot produce insulin or cannot properly use the insulin it produces. Type 1 diabetes occurs when the immune system mistakenly attacks and kills the beta cells of the pancreas. Type 2 diabetes occurs when the body can't properly use the insulin that is released (called insulin insensitivity) or does not make enough insulin. Diabetic nephropathy, also known as Kimmelstiel Wilson syndrome or nodular diabetic glomerulosclerosis or intercapillary glomerulonephritis, is a clinical syndrome characterized by albuminuria $(>300 \mathrm{mg} /$ day or $>200$ $\mathrm{mcg} / \mathrm{min}$ ), permanent and irreversible decrease in glomerular filtration rate (GFR), the rate of rise in serum creatinine ( $\mathrm{SrCr}$ ). According to the $\mathrm{WHO}, 31.7$ million people were affected by diabetes mellitus (DM) in India in the year 2000. This figure is estimated to rise to 79.4 million by 2030, the largest number in any nation in the world. In this paper, survival analysis will be done of the type 2 diabetic nephropathy patients through generalized linear model. Most appropriate distribution for duration of diabetes is selected through Bayesian information criterion value. Then two generalized linear models are fitted by taking the duration of diabetes as response variable and the predictors as SrCr, number of successes; GFR, number of successes, respectively. These covariates are linked with the response variable using different link functions. At the last, survival function under different links will be compared.

KEY WORDS: Generalized linear model, Link function, Bayesian information criterion, Survival function, Diabetic nephropathy, GFR

- HOW TO CITE THIS PAPER : Ismail, Yasmeena, Mir, S.A., Bhat, M.A and Nazir, Nageena (2018). An application of generalized linear model in survival analysis. Asian J. Home Sci., 13 (1) : 68-74, DOI: 10.15740/HAS/AJHS/13.1/68-74. Copyright@ 2018: Hind Agri-Horticultural Society. 